\title{
Effect of surface treatments on color of machinable ceramics
}

\author{
Amna Salem ${ }^{1 *}$, Cherif Mohsen ${ }^{2}$ \\ ${ }^{1}$ Department of Fixed Prosthodontics, Faculty of Dentistry, Assiut University, 71515 Assiut, Egypt \\ ${ }^{2}$ Department of Fixed Prosthodontics, Faculty of Dentistry, Minia University, 61519 Minia, Egypt \\ *Correspondence: amna.salem85 @ gmail.com; Tel: +2 0862423425; Fax: +20 882350113
}

\section{Article information \\ Received: 9 May 2020 \\ Revised: 23 June 2020 \\ Accepted: 24 June 2020 \\ Key words \\ Lithium disilicate \\ Suprinity \\ Surface treatment \\ Spectrophotometer \\ Color}

\begin{abstract}
Aim: The purpose of this study is to evaluate the effect of surface treatments on color of lithium disilicate ceramic (IPS e. max [CAD]) and hybrid ceramic (VITA Suprinity [pc]).

Method: Ceramic blocks were sectioned in to one hundred sixty discs; eighty discs of lithium disilicate were randomly subdivided in to four groups according to surface treatment $(n=20)$. Group $C$ : Control group without surface treatment; group I: using $\left(\mathrm{AL}_{2} \mathrm{O}_{3}\right)$ particles size $50 \mu \mathrm{m}$; group II: Hydro fluoric (HF) acid etching; group III: tribochemical (TBC) surface treatment. Eighty discs of hybrid ceramic $(n=20)$ were subdivided in to the same groups. Color measurements were performed with spectrophotometer and repeated after surface treatments. $\Delta \mathrm{E}$ values were statistically analyzed with one- way ANOVA, Tukey's post hoc test was done to identify significance between groups. Statistically significance was considered when $\mathrm{P}$ value $\leq 0.05$.

Results: Changing color of lithium disilicate specimens were not clinically perceptible except for hydrofluoric acid etching as it was below the clinically accepted threshold $(\Delta \mathrm{E}<2.7)$. Suprinity hydrofluoric acid etching specimens color changes were clinically acceptable $\Delta \mathrm{E}<2.7$ but air abrasion with $\mathrm{Al}_{2} \mathrm{O}_{3}$ $50 \mu \mathrm{m}$ and tribochemical surface treatment specimens showed $\Delta \mathrm{E}>2.7$ which were clinically unaccepted.

Conclusion: Different techniques; sand blasting, $\mathrm{HF}$ acid etching and tribochemical surface treatments affected color significantly.
\end{abstract}

\section{Introduction}

All ceramic restorations are recommended from dentist and favorable for patients because of their esthetic and durability in conservative tooth preparations [1].

Now a day, ceramics are mainly lithium disilicate- based computer- aided design, computer/aided manufacturing (CAD/CAM) blocks [2].

Recently, a new material, zirconia- reinforced (lithium silicate) ceramic (ZLS), was introduced to the market under argument that zirconia could act as a crystal phase that can reinforce the material; that is, avoid crack propagation. This material could be etched with hydrofluoric acid as a ceramic matrix is predominantly glass with zirconia (8\%-12\%) [3].

Proper adhesion between a luting agent and a ceramic restoration requires surface pretreatment. Powerful resin bond depends on chemical adhesion and micro mechanical interlocking to the ceramic restoration surface, which needs surface roughening for adequate surface activation [4].

To reach this bond, the ceramic surface might be modified chemically, mechanically or by laser to promote surface roughness and/or reactivity of the porcelain to the luting agent. Air abrasion with aluminium oxide particles using a chair side device is one of the techniques of surface treatment to increase micro mechanical retention [5].
The use of hydro fluoric acid etching of ceramic surface resulted in alternative surface by selectively etching the glass matrix [6]. Roughening of the surface by tribochemical surface treatment is considered reliable method using aluminium oxide particles with silica coating and silane application [2].

As surface treatment is important step in bonding, color changes of restorative material should be considered.

\section{Hypothesis}

Different surface treatment techniques affect the color of lithium disilicate (IPS e. $\max$ [CAD]) and hybrid (VITA Suprinity [pc]) ceramics.

\section{Materials and Methods}

Two types of ceramic used in this study; Lithium disilicate (IPS e- max, CAD Ivoclar Vivadent AG. Schaan. Liechtenstein. USA) was shown in (Table 1). Hybrid ceramic (VITA SUPRINITY pc. VITA Zahnfabric. Spitaglasse 3. Bad Säkingen. Germany) was shown in (Table 2).

\subsection{Preparation of ceramic samples}

One hundred sixty discs (five $\mathrm{mm}$ in diameter and two $\mathrm{mm}$ thick) were fabricated of the two types of ceramic; eighty discs of lithium disilicate (L.D) and eighty discs of hybrid ceramic 
(H.C) then discs were had crystallization in a furnace at a proper temperature according to manufacturer's instructions. All specimens were polished under constant water irrigation with 600- grit followed by 1000 and 1200 grit wet silicon carbide paper (Klingspor abrasives Inc. Hickory. NC).

Table 1: Chemical composition of IPS e- max CAD

\begin{tabular}{lc}
\hline \multicolumn{1}{c}{ Standard composition } & (in \% by weight) \\
\hline $\mathrm{SiO2}$ & $57.0-80.0$ \\
$\mathrm{Li20}$ & $11.0-19.0$ \\
$\mathrm{~K} 20$ & $0.0-13.0$ \\
$\mathrm{P2O3}$ & $0.0-11.0$ \\
$\mathrm{ZrO2}$ & $0.0-8.0$ \\
$\mathrm{ZnO}$ & $0.0-8.0$ \\
$\mathrm{Al2O3}$ & $0.0-5.0$ \\
$\mathrm{MgO}$ & $0.0-5.0$ \\
Coloring oxides & $0.0-8.0$ \\
\hline
\end{tabular}

Table 2: Chemical composition of VITA Suprinity PC

\begin{tabular}{lc}
\hline \multicolumn{1}{c}{ Standard composition } & (in \% by weight) \\
\hline $\mathrm{ZrO}_{2}$ & $8-12$ \\
$\mathrm{SiO}_{\mathbf{2}}$ & $56-64$ \\
$\mathrm{Li}_{2} \mathrm{O}$ & $15-21$ \\
$\mathrm{La}_{2} \mathbf{O}_{3}$ & 0.1 \\
pigments & $<10$ \\
various & $>10$ \\
\hline
\end{tabular}

\subsection{Surface treatments}

Lithium disilicate Discs were then randomly subdivided in to four groups according to the surface treatment $(n=20)$. L.D (C): Control group without any surface treatment. L.D I: using $\left(\mathrm{AL}_{2} \mathrm{O}_{3}\right)$ particles size $50 \mu \mathrm{m}$; L.D II: Hydro fluoric acid etching; L.D III: tribochemical surface treatment. Hybrid ceramic discs were randomly subdivided in to four groups according to surface treatments $(n=20)$. H.C $(C)$ : control group without any surface treatment; H.C I: air abrasion using $\left(\mathrm{AL}_{2} \mathrm{O}_{3}\right)$ particles size $50 \mu \mathrm{m}$; H.C II: hydro fluoric acid etching; H.C III: tribochemical surface treatment.

Air abrasion was done using aluminium oxide particles $\mathrm{Al}_{2} \mathrm{O}_{3}$ size 50 $\mu \mathrm{m}$ (Korox. Bego. Bremen. Germany) using a chair side sand blasting device (prep star. Danvell instrument. CA. USA) at a pressure of 2.8 bars, from a distance of $10 \mathrm{~mm}$, perpendicular to the treated surface for $20 \mathrm{~s} \mathrm{[7].}$

Hydrofluoric acid etching of the samples was done by using (9.5\%) Buffered Hydrofluoric Acid Gel. Bisco. Schaumburg. U.S.A) for 20 seconds, then rinsed with distilled water for one minute, ultrasonically cleaned in distilled water for one minute and finally dried with compressed oil- free water/ air spray [8]. Tribochemical surface treatment was done by first cleaning the treated surface with $110 \mu \mathrm{m}$ aluminium oxide sand (Korox.
Bego. Bremen. Germany) at a pressure of 2.8 bars, from a distance of $10 \mathrm{~mm}$, perpendicular to the treated surface for $15 \mathrm{~s}$. Then the surface was micro blasted with silica- modified aluminium oxide using a chair side sand blasting device (prep star. Danvell instrument. CA. USA) $\left(110 \mu \mathrm{m} \mathrm{Al}{ }_{2} \mathrm{O}_{3}\right.$ and $30 \mu \mathrm{m}$ $\mathrm{SiO}_{2}$ ) at a pressure of 2.8 bars, from a distance of $10 \mathrm{~mm}$, perpendicular to the treated surface for $15 \mathrm{~s}$. The next step was silanization with (Rely X ceramic primer. 3M ESPE., USA) for 5 minutes. Apply silane coupling agent to the treated ceramic surface then, gently oil free air was blown across the surface [9].

\subsection{SEM observation}

Ceramic discs were fixed on stubs that were sputter- coated with gold with thickness $40 \AA$ (Desk II. Denton vacuum Inc. NJ) and scanned by SEM at 2000 magnification (JSM- 5600 LV; JEOL. Tokyo. Japan).

\subsection{Color measurements}

Color measurements of all specimens were done using spectrophotometer (VITA easy shade compact. VITA Zahnfabric). According to instructions of manufacturer, calibration done for the device using (tooth single) measurement mode was chosen and the probe was placed in the specimen center. The mean $L^{*}, a^{*}$ and $b^{*}$ values were calculated for each specimen. Color difference was calculated for all groups on the gray backing to analyze the effect of surface treatment with the following equation:

$$
\Delta \mathrm{E}=\left[(\Delta \mathrm{L} *)^{2}+\left(\Delta \mathrm{a}^{*}\right)^{2}+\left(\Delta \mathrm{b}^{*}\right)^{2}\right]^{1 / 2}
$$

$\Delta \mathrm{E}$ value $>1.2$ was considered perceptible and $\Delta \mathrm{E}$ value $>2.7$ was clinically unaccepted.

\section{Statistical analysis}

$\Delta \mathrm{E}$ value were analyzed with one- way ANOVA, Post- hoc comparison were done. Statistically significance was considered when $P$ value $\leq 0.05$.

\section{Results}

\subsection{SEM evaluation}

Representative SEM images of Lithium disilicate (IPS e. $\max [\mathrm{CAD}]$ ) and Hybrid ceramic (VITA Suprinity [pc]) groups are reported in (Figures 1-2). The control groups revealed homogenous structures. HF acid etching groups of both types of ceramic showed much rough surface than control groups with micro porous appearance. A large number of voids as dissolution of the glass phase of ceramics. Sand blasting with $\mathrm{AL}_{2} \mathrm{O}_{3}$ and tribochemical surface treatment groups revealed similar surface of various irregular retentive areas with gaps and grooves on surface. Tribochemical surface treated groups showed finer texture. 

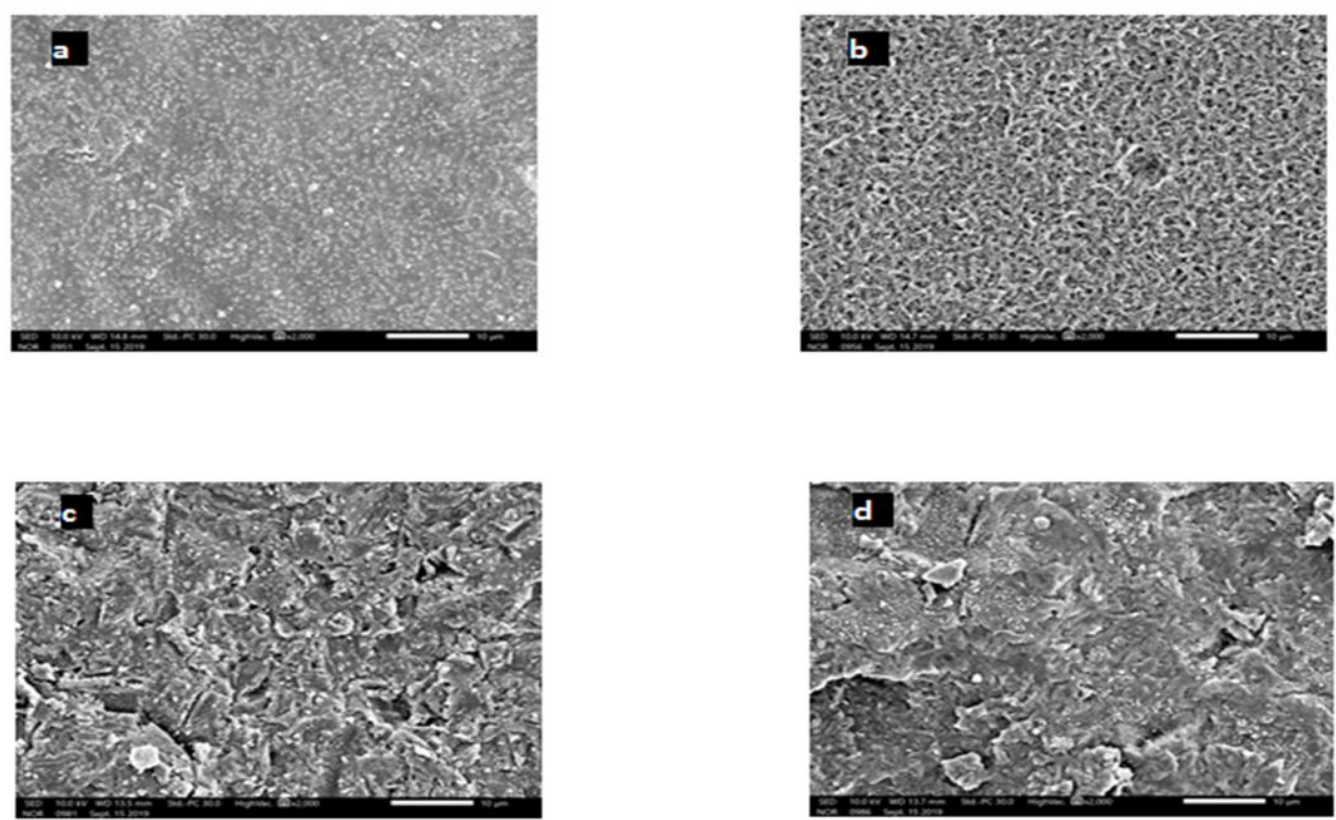

Figure 1: SEM images of Lilthium disilicate (IPS e. max CAD) surface treatments: (a) control (b) $\mathrm{HF}$ acid etching (c) $\mathrm{AL}_{2} \mathrm{O}_{3}$ sand blating (d) TBC
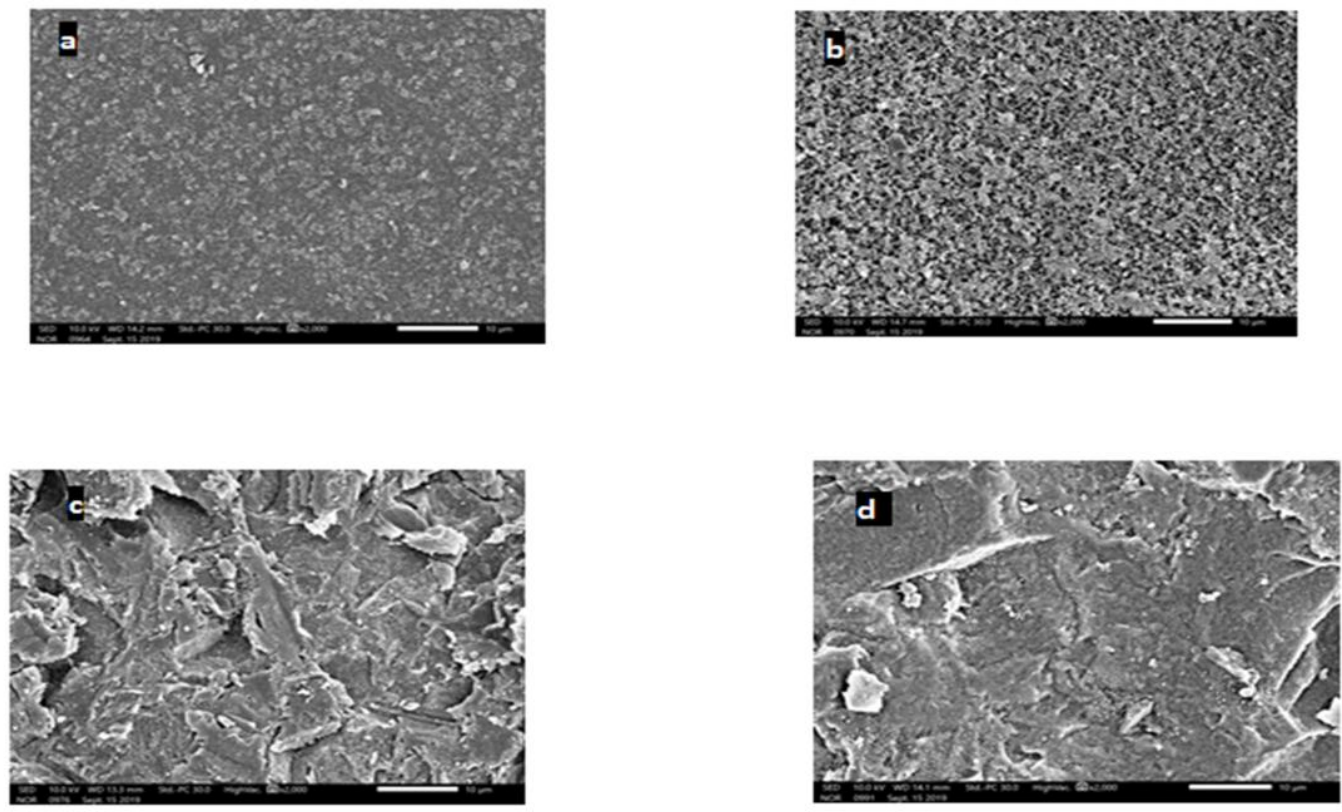

Figure 2: SEM images of Hybrid ceramic (VITA Suprinity PC) surface reatments: (a) control (b) HF acid etching (c) $\mathrm{AL}_{2} \mathrm{O}_{3}$ sand blating (d) TBC 


\subsection{Color measurements}

$\Delta \mathrm{E}$ values of lithium disilicate for all surface treatment groups were not clinically perceptible as $\Delta \mathrm{E}$ values $<1.2(0.622$ and 1.164 for $\mathrm{Al}_{2} \mathrm{O}_{3}$ sand blasting and tribochemical respectively) except for hydrofluoric acid etching specimens as $\Delta \mathrm{E}<2.7$ were below the clinical acceptable threshold. Hydrofluoric acid etching suprinity specimens showed $\Delta \mathrm{E}$ values below $2.7(\Delta \mathrm{E}<2.7)$ which were below the clinically acceptable threshold. $\Delta \mathrm{E}$ values for $\mathrm{Al}_{2} \mathrm{O}_{3}$ sandblasting and tribochemical specimens were above $2.7(\Delta \mathrm{E}>2.7)$ which were clinically unacceptable as $\Delta \mathrm{E}$ values were 4.701 and 7.293 respectively. There was significant difference in $\Delta \mathrm{E}$ values between different surface treatment groups of each type of ceramic $\mathrm{p}$ value $\leq 0.05$ as shown in (Table 3). As showed in (Figure 3) there was significant difference between the three surface treatments groups in $\Delta \mathrm{E}$ values $(\mathrm{P}$ value $\leq 0.05)$. HF acid etching group showed the highest mean $\Delta \mathrm{E}$ value which was (2.7) while $\mathrm{AL}_{2} \mathrm{O}_{3}$ sand blasting was the lowest value which was (0.6). In (Figure 4) there was significant difference between groups $(\mathrm{P}$ value $\leq 0.05)$. The highest $\Delta \mathrm{E}$ value was for tribochemical surface treatment group which was (3.7) and the lowest value for HF acid etching group (1.9).

\section{Discussion}

Developments in CAD/CAM technology have led to introduce ceramic materials with mechanical and optical properties. Enhancing bonding with all ceramic restoration requires conditioning of fitting surface of dental restoration. Bond strength and optical properties of ceramics have been affected by different techniques of surface treatment [10-11]. There for our study investigated the effect of different surface treatment techniques on the color of current CAD/CAM lithium disilicate and hybrid ceramic materials. Optical properties knowledge of current CAD/CAM restorative materials is important to improve esthetic appearance of the monolithic restorations [12]. Optical two main thresholds were used for evaluation of color differences, perceptibility and acceptability. Assessment of $\Delta \mathrm{E}$ values for ceramic materials was done using different thresholds. In this study clinically perceptibility threshold was 1.2 and clinical acceptance one was 2.7, according to the results of recent published study of perceptive multicenter [13]. Different techniques of surface treatment for lithium disilicate ceramics gave color changes within the clinical acceptable range [14]. $\Delta \mathrm{E}$ values of hydrofluoric acid etching of suprinity specimens were within the range of color

Table 3: Color difference $\Delta \mathbf{E}$ values of Lithium disilicate and suprinity ceramics

\begin{tabular}{|c|c|c|c|c|c|c|}
\hline & $\begin{array}{c}\text { Group I } \\
\text { Al2O3 }(50 \mu \mathrm{m})\end{array}$ & $\begin{array}{c}\text { Group II } \\
\text { H.F }\end{array}$ & $\begin{array}{c}\text { Group III } \\
\text { TBC }\end{array}$ & \multicolumn{3}{|c|}{$P$ - value } \\
\hline Lithium disilicate (L.D) & & & & \multicolumn{3}{|c|}{$<0.001 *$} \\
\hline Range & $0.24-1$ & $2.33-3.21$ & $1.02-1.33$ & I vs II & I vs III & II vs III \\
\hline Mean \pm SD & $0.6 \pm 0.3$ & $2.7 \pm 0.35$ & $1.2 \pm 0.13$ & $<0.001 *$ & $0.010 *$ & $<0.001 *$ \\
\hline Suprinity (H.C) & & & & \multicolumn{3}{|c|}{$<0.001 *$} \\
\hline Range & $4.27-5.2$ & $1.62-2.13$ & $5.16-9.07$ & I vs II & I vs III & II vs III \\
\hline Mean $\pm \mathrm{SD}$ & $4.7 \pm 0.4$ & $1.9 \pm 0.19$ & $7.3 \pm 1.5$ & $<0.001 *$ & $0.001 *$ & $<0.001 *$ \\
\hline
\end{tabular}

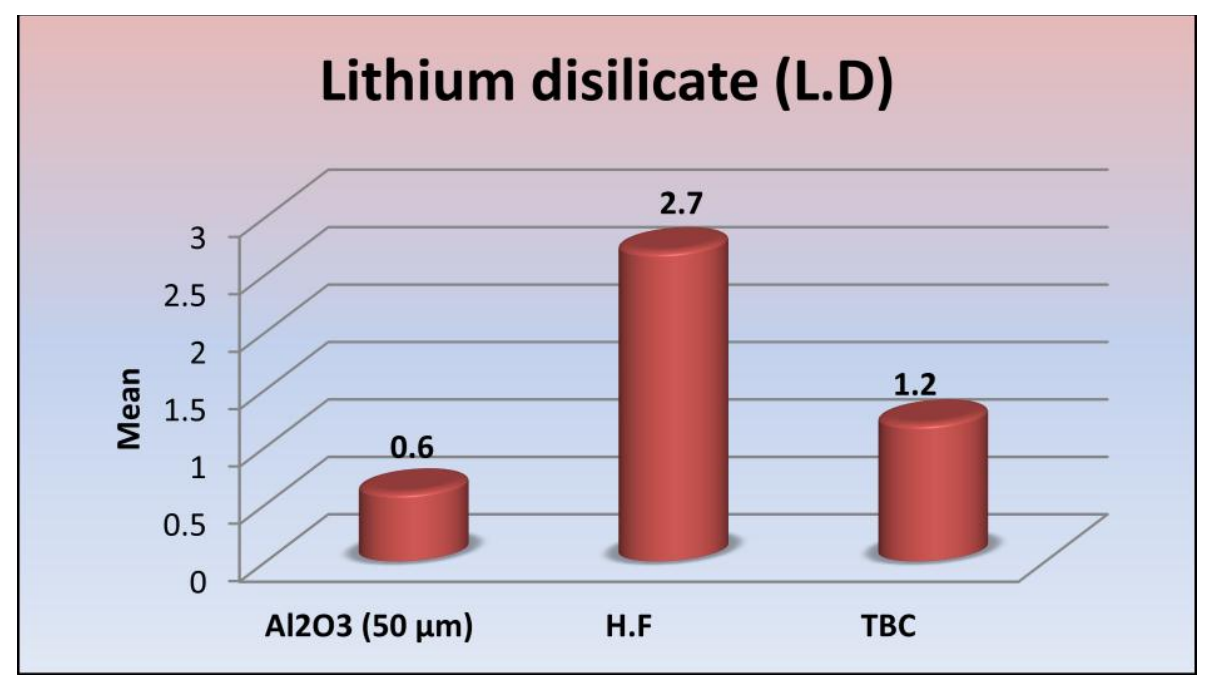

Figure 3: Statistical analysis of color of lithium disilicate (IPS e. max CAD) 


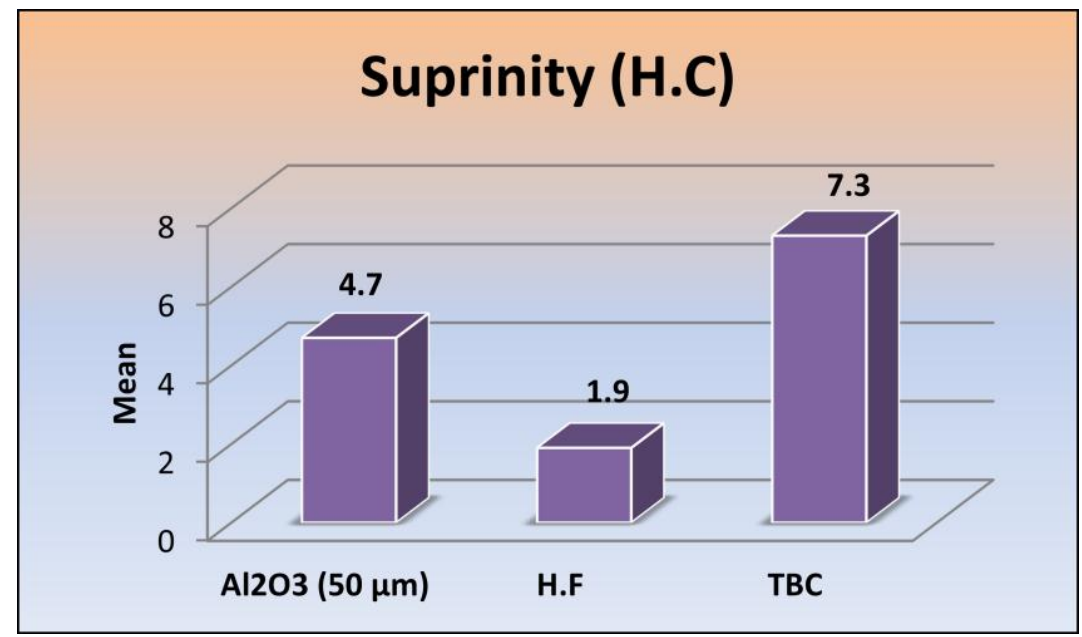

Figure 4: Statistical analysis of color of Hybrid ceramic (VITA Suprinity PC)

clinical acceptance. Sandblasting and tribochemical surface treatments $\Delta \mathrm{E}$ values were not clinically accepted as lower hardness of suprinity ceramic material led to increasing in irregularities and excessive gaps on surface that result in diffusion and scattering of light at different angles [15]. In this study color difference of all ceramic materials were evaluated without presence of resin cement, which is a limitation. Another limitation is that the specimens were not subjected to the thermal cycling or aging which can better simulate the oral condition. Within the limitation of this study, it can find that Surface treatments have significant effect on color of CAD/CAM ceramic materials. Hydrofluoric acid etching, $\mathrm{Al}_{2} \mathrm{O}_{3}$ air abrasion and tribochemical surface treatment techniques could be used with lithium disilicate ceramic. $\mathrm{Al}_{2} \mathrm{O}_{3}$ sand blasting and tribochemical surface treatments were not recommended techniques for surface treatment of suprinity ceramic material as color changes were not clinically acceptable.

\section{Conclusion}

Different techniques; sand blasting with $50 \mu \mathrm{m} \mathrm{AL}_{2} \mathrm{O}_{3}, \mathrm{HF}$ acid etching and tribochemical surface treatments affected color significantly. For Lithium disilicate ceramic the three techniques of surface treatment could be used, also HF acid etching could be used with VITA Suprinity [pc] but sand blasting with $50 \mu \mathrm{m} \mathrm{AL}_{2} \mathrm{O}_{3}$ nor tribochemical surface treatments shouldn't be used as they were clinically unaccepted.

\section{References}

[1] Özcan M, Nijhuis H, Valandro LF. Effect of various surface conditioning methods on the adhesion of dual-cure resin cement with MDP functional monomer to zirconia after thermal aging. Dental Materials Journal. 2008; 27:99-104.

[2] Sato TP, Anami LC, Melo RM, Valandro LF, Bottino MA. Effects of surface treatments on the bond strength between resin cement and a new zirconia-reinforced lithium silicate ceramic. Operative dentistry. 2016; 41:28492.

[3] Özdemir H, Aladağ Lİ. Effect of different surface treatments on bond strength of different resin cements to lithium disilicate glass ceramic: an in vitro study. Biotechnology \& Biotechnological Equipment. 2017; 31:815-20.
[4] Borges GA, Sophr AM, De Goes MF, Sobrinho LC, Chan DC. Effect of etching and airborne particle abrasion on the microstructure of different dental ceramics. The Journal of prosthetic dentistry. 2003; 89:479-88.

[5] Plueddemann EP. Adhesion through silane coupling agents. The Journal of Adhesion. 1970; 2:184-201.

[6] Wood DJ, Bubb NL, Millar BJ, Dunne SM. Preliminary investigation of a novel retentive system for hydrofluoric acid etch-resistant dental ceramics. The Journal of prosthetic dentistry. 1997; 78:275-80.

[7] Kara HB, Dilber E, Koc O, Ozturk AN, Bulbul M. Effect of different surface treatments on roughness of IPS Empress 2 ceramic. Lasers in medical science. 2012; 27:267-72.

[8] Ren DF, Luo XP. Effect of hydrofluoric acid etching time and resin bonding on the flexural strength of lithium disilicate glass ceramic. Zhonghua kou qiang yi xue za zhi= Zhonghua kouqiang yixue zazhi $=$ Chinese journal of stomatology. 2013; 48:462-6.

[9] Özdemir H, Aladağ L L̇. Effect of different surface treatments on bond strength of different resin cements to lithium disilicate glass ceramic: an in vitro study. Biotechnology \& Biotechnological Equipment. 2017; 31:815-20.

[10] Turgut S, Bağış B, Korkmaz FM, Tamam E. Do surface treatments affect the optical properties of ceramic veneers?. The Journal of prosthetic dentistry. 2014; 112:618-24.

[11] Menees TS, Lawson NC, Beck PR, Burgess JO. Influence of particle abrasion or hydrofluoric acid etching on lithium disilicate flexural strength. The Journal of prosthetic dentistry. 2014; 112:1164-70.

[12] Stawarczyk B, Liebermann A, Eichberger M, Güth JF. Evaluation of mechanical and optical behavior of current esthetic dental restorative $\mathrm{CAD/CAM}$ composites. Journal of the mechanical behavior of biomedical materials. 2016; 55:1-1.

[13] Paravina RD, Ghinea R, Herrera LJ, Bona AD, Igiel C, Linninger M, Sakai M, Takahashi H, Tashkandi E, Mar Perez MD. Color difference thresholds in dentistry. Journal of Esthetic and Restorative Dentistry. 2015; 27:S1-9.

[14] Kurtulmus-Yilmaz S, Cengiz E, Ongun S, Karakaya I. The effect of surface treatments on the mechanical and optical behaviors of CAD/CAM restorative materials. Journal of Prosthodontics. 2019; 28:e496-503.

[15] Ataol AS, Ergun G. Effects of surface treatments on repair bond strength of a new CAD/CAM ZLS glass ceramic and two different types of CAD/CAM ceramics. J Oral Sci 2008; 60:201-11. 